University of Nebraska - Lincoln

DigitalCommons@University of Nebraska - Lincoln

Agronomy \& Horticulture -- Faculty Publications

Agronomy and Horticulture Department

May 2006

\title{
Features, Applications, and Limitations of the Hybrid-Maize Simulation Model
}

\author{
Haishun Yang \\ University of Nebraska-Lincoln, hyang2@unl.edu \\ Achim Dobermann \\ Kenneth G. Cassman \\ University of Nebraska-Lincoln, kcassman1@unl.edu \\ Daniel T. Walters \\ University of Nebraska-Lincoln, dwalters1@unl.edu
}

Follow this and additional works at: https://digitalcommons.unl.edu/agronomyfacpub

Part of the Plant Sciences Commons

Yang, Haishun; Dobermann, Achim; Cassman, Kenneth G.; and Walters, Daniel T., "Features, Applications, and Limitations of the Hybrid-Maize Simulation Model" (2006). Agronomy \& Horticulture -- Faculty Publications. 94.

https://digitalcommons.unl.edu/agronomyfacpub/94

This Article is brought to you for free and open access by the Agronomy and Horticulture Department at DigitalCommons@University of Nebraska - Lincoln. It has been accepted for inclusion in Agronomy \& Horticulture -Faculty Publications by an authorized administrator of DigitalCommons@University of Nebraska - Lincoln. 


\title{
Features, Applications, and Limitations of the Hybrid-Maize Simulation Model
}

\author{
Haishun Yang,* Achim Dobermann, Kenneth G. Cassman, and Daniel T. Walters
}

\begin{abstract}
The objective of this paper is to provide an overview of the HybridMaize software (www.hybridmaize.unl.edu, verified 28 Feb. 2006), with emphasis on its practical applications based on our own experience and feedback from users. The Hybrid-Maize model is a computer program that simulates the growth and yield of a corn crop (Zea mays L.) under nonlimiting or water-limited (rainfed or irrigated) conditions. The scientific formulations of the model and its test and validation was published elsewhere. The model can be used to (i) assess the overall site yield potential and its variability based on historical weather data, (ii) evaluate changes in attainable yield using different combinations of planting date, hybrid maturity, and plant density, (iii) analyze yield in relation to silking and maturity in a specific year, (iv) assess soil moisture status and explore options for irrigation management, and (v) conduct in-season simulations to evaluate current crop status and predict final yield at maturity as a range of yield outcome probabilities based on historical climate data for the remainder of the growing season. Three examples are provided to demonstrate practical uses of the model. The software has a user-friendly graphic interface, and includes complete documentation of model formulations, validation, user manual, and context-sensitive help system. Settings of all internal parameters are transparent and modifiable by the user. Limitations of the software for practical uses, especially with regard to water stress and plant population, are also discussed.
\end{abstract}

$\mathrm{C}$ ROP SIMULATION MODELS synthesize our current quantitative understanding of crop growth and development in response to environmental conditions and management. They have the potential to serve a wide range of applications, including research, teaching, and extension education as well as decision-support for identifying promising options for changes in crop, soil, and water management in production fields (Hammer et al., 2002). Although several models are currently available for corn, for example, DSSAT (Jones et al., 2003), ALMANAC (Kiniry and Bockholt, 1998), INTERCOM (Kropff and van Laar, 1993), STICS (Brisson et al., 2003), some are better suited for research while others were designed for decision-support. For some of these models, input data are difficult to obtain or require detailed empirical measurements to establish hybrid-specific genetic coefficients as inputs to run the model. In other cases, user support documentation is lacking, which inhibits use by people outside the group that developed the model.

Given this situation, there is a need for developing crop models that are robust in performance, easy to use,

Dep. of Agronomy and Horticulture, Univ. of Nebraska-Lincoln, P.O. Box 830915, Lincoln, NE 68583. Received 26 May 2005. *Corresponding author (hyang2@unl.edu).

Published in Agron. J. 98:737-748 (2006).

Software

doi:10.2134/agronj2005.0162

(c) American Society of Agronomy

677 S. Segoe Rd., Madison, WI 53711 USA flexible in parameter settings, transparent in formulation and well supported with a comprehensive user's guide and program documentation. Moreover, to facilitate the use of crop models among clientele with diverse needs and/or computer literacy, it is desirable for the models to come equipped with auxiliary functions and utilities that facilitate data handling (e.g., weather data acquisition, proofing, and formatting) and intuitive presentation of model ouput.

We have recently developed a new corn simulation model, Hybrid-Maize. Details about this model and its validation are published elsewhere (Yang et al., 2004a, 2004b). Briefly, the Hybrid-Maize model builds on the strengths of existing models by combining the cropspecific attributes of CERES-Maize (Jones and Kiniry, 1986; Kiniry et al., 1997) related to phenology and organ growth with explicit photosynthesis and respiration functions from assimilate-driven generic crop models such as SUCROS, WOFOST, and INTERCOM (van Diepen et al., 1989; Kropff and van Laar, 1993; van Ittersum et al., 2003). Hybrid-Maize also includes additional modifications for several functions based on calibration with experimental data from a field study that produced maize with minimal possible stress - conditions that are required to achieve yield potential (Yang et al., 2004a). Since its release in August 2004, the model is being used by researchers, extension specialists and educators, crop consultants, industry professionals, and farmers. The objective of this paper is to provide an overview of the Hybrid-Maize software, with emphasis on its capabilities and potential applications based on our own experience and feedback from users. We also discuss limitations of the model and opportunities for future improvement.

\section{FEATURES OF THE HYBRID-MAIZE SOFTWARE}

The current version of the Hybrid-Maize model simulates potential corn growth and yield under nonlimiting or water-limited conditions. Specifically, it allows users to: (i) assess the site yield potential and its variability based on historical weather data, (ii) evaluate changes in attainable yield using different combinations of planting date, hybrid maturity, and plant density, (iii) analyze corn yield in relation to the timing of silking and maturity in specific years, (iv) assess soil moisture status and explore options for irrigation management, and (v) conduct in-season simulations to evaluate current crop status and predict final yield at maturity as a range of yield-outcome probabilities based on historical climate data for the remainder of the growing season.

Abbreviations: CRM, comparative relative maturity; DAE, days after emergence; GDD, growing degree days; HPRCC, High Plains Regional Climate Center; LAI, leaf area index. 
The current version of the program does not account for nutrient limitations or yield loss from weeds, insects, diseases, lodging, and stresses other than the effects of solar radiation, temperature, and soil-plant water relations.

To support research applications, the Hybrid-Maize model is transparent in formulation, flexible in parameter settings, and comprehensive in documentation to facilitate model validation and further development. It provides tools to evaluate crop growth during the growing season and at maturity in terms of dry matter accumulation in roots, stems, leaves, and developing grain. It also provides information that helps explain crop performance, such as gross assimilation, respiration, actual evapotranspiration, and soil moisture depletion in the root zone. To facilitate its use in crop management decisions, on the other hand, the model also is designed to be easy to operate with a minimum number of input variables compared to other corn simulation models. It has a user-friendly input and output interface and auxiliary functions and utilities that facilitate data file handling such as weather data compilation, unit conversion, editing/saving/retrieving of model settings, default parameters, and output. To avoid unrealistic simulations, Hybrid-Maize confines input settings to reasonable limits or provides warning messages when input values fall outside the range of conditions for which the model has been validated.

\section{User Interface Features}

A flowchart of input settings, operation, and presentation of model outputs is presented in Fig. 1, and these components are implemented through a multi-page graphical user interface (Fig. 2). These pages are identified by seven tabs: (1) 'Input' for input and simulation mode settings, (2) 'Results' for summary of numerical outputs, (3) 'Chart' for display of any of 17 output variables for across-run comparisons, (4) 'Growth' for graphical display of growth dynamics of eight variables, (5) 'Weather' for display of growing season climate data, (6) 'Water' for growing season soil moisture regime and crop water stress index, and (7) 'Yield trend' for displaying trends in in-season yield forecasts. Most input settings have multiple choices, and some choices determine the need for additional input parameters. Therefore, only 'live' input boxes are accessible depending on selection of a particular simulation mode while input boxes for parameters that are not needed are grayed out and inaccessible. For example, if the 'Optimal' water

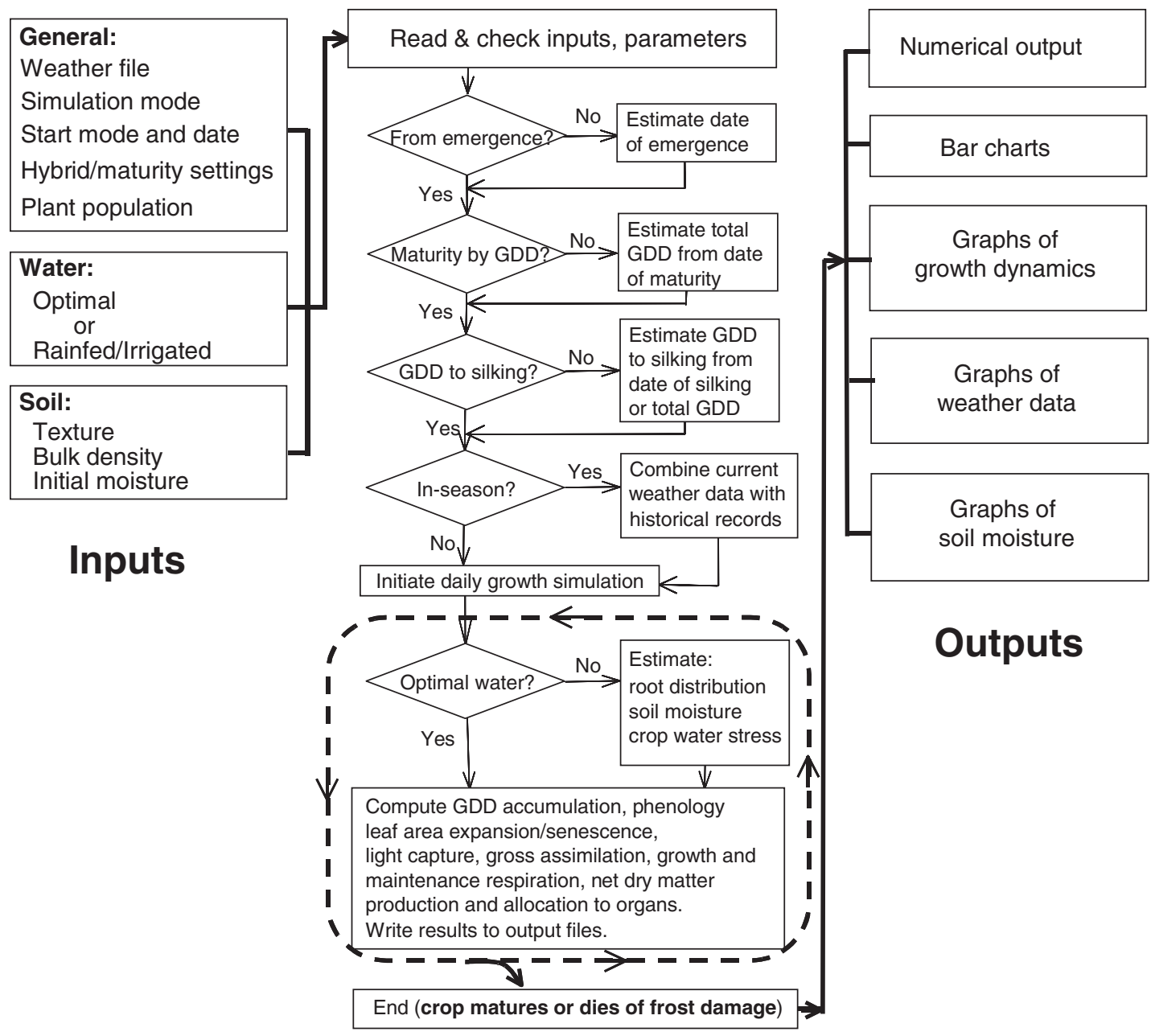

Fig. 1. Operational flow of the Hybrid-Maize model. GDD = growing degree days. 


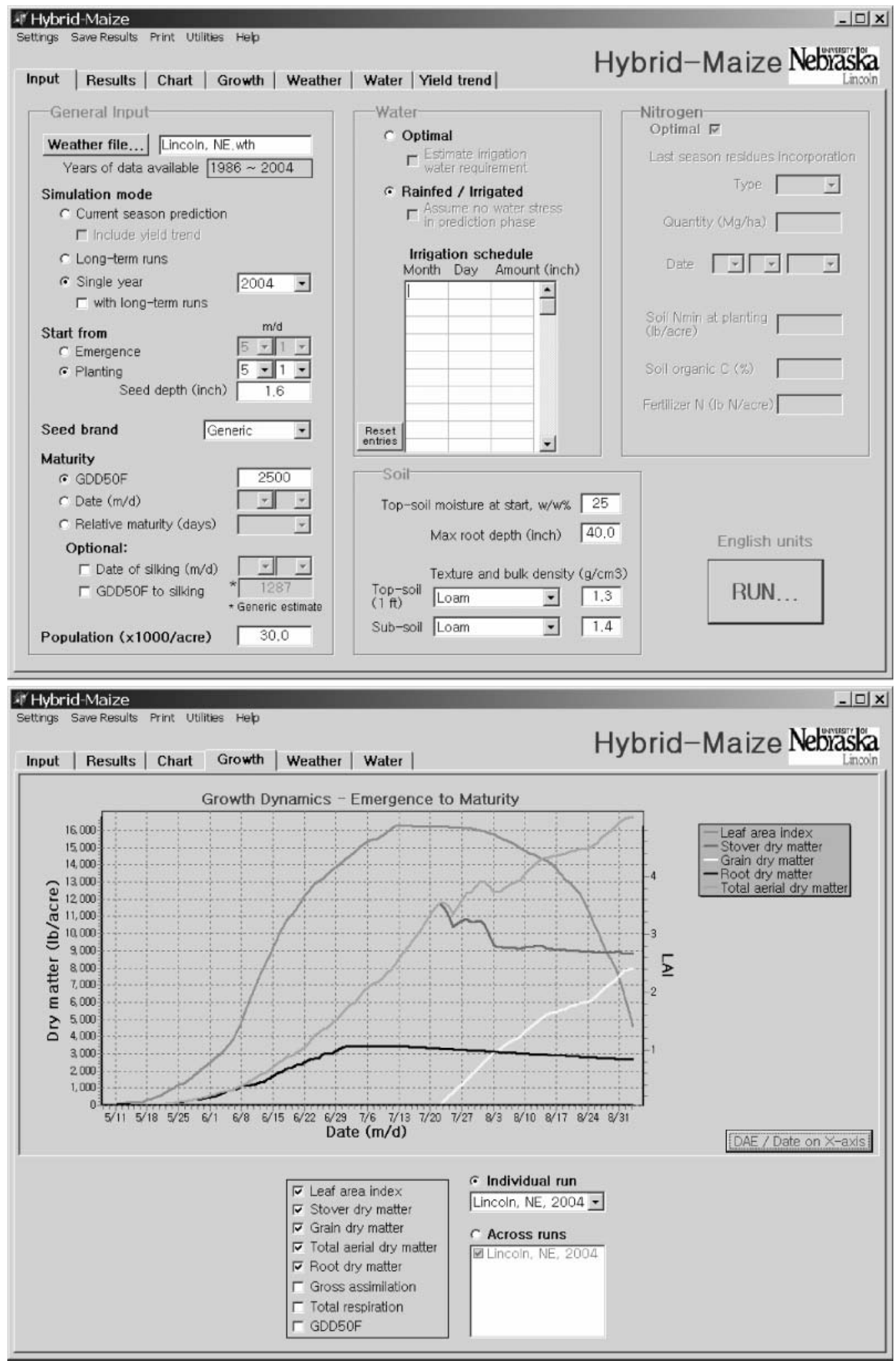

Fig. 2. Screenshots of the input page (top) and one of the five output pages (bottom) of the Hybrid-Maize model.

regime is selected as the simulation mode, then the input boxes for irrigation timing and soil properties are not accessible as they are not needed.

The software offers the choice of either metric or English units for input and output variables. Once the units have been selected, all related text in titles and captions change accordingly to match the selected units. For time-dependent graphs (i.e., Growth, Weather, and Water in Fig. 2), the time scale can be toggled with a click of a button between days after emergence (DAE) 
or calendar date. The DAE format is especially useful when graphically comparing simulations from different latitudes.

A unique feature of Hybrid-Maize is that all key internal model parameters are accessible to the user (Fig. 3). Each parameter has a text description and some have references to journal papers from which default values were obtained or derived. The user can modify the values for each of these parameters, but there is also the option of restoring all of the original default values with a single mouse click.

Simulation settings for a given site can be saved in a working file so that the user can retrieve these settings for future simulation runs. Graphs can also be printed for future reference. The numerical output from the 'Results' screen can be directly edited on-screen, opened in MS Excel or saved as an Excel file.

The software includes a context-sensitive help system that can be accessed by pressing F1 on the keyboard or through a pull-down Help menu. Other utilities include easy access to changing the settings for the initial default values for input parameters, folders for working files and weather files, saving and retrieving of input settings from past simulation runs, and saving and printing of simulation results. Window's default text editor and calculator can also be brought up directly within Hybrid-Maize without exiting the software. A complete publication list of all citations used as background information for developing model formulations and default input parameter settings and a printable users manual with examples of potential applications are provided in the Help menu.

\section{MODEL INPUT REQUIREMENTS Weather Data}

A weather file for the site to be simulated must be selected to begin a simulation run. Hybrid-Maize requires daily weather data in metric units. For simulation under optimal conditions, Hybrid-Maize requires three weather variables: total solar radiation (in $\mathrm{MJ} \mathrm{m}^{-2}$ ), minimum air temperature and maximum air temperature (in ${ }^{\circ} \mathrm{C}$ ). For water-limited conditions (rainfed or irrigated simulation mode), three additional variables are required: rainfall (in $\mathrm{mm}$ ); potential evapotranspiration (in $\mathrm{mm}$ ); and relative air humidity (in \%). The weather data must cover the entire growing season from either the date of planting or emergence day to physiological maturity (black layer).

Preparation and error checking of weather data is one of the most difficult tasks required before any crop model can be used. In Hybrid-Maize, the weather file is a text file and its format is flexible in terms of data positioning. One file contains all years of weather data for a single site with text description of the site as well as titles and units for variables. For users within the coverage of the High Plains Regional Climate Center (HPRCC, www.hprcc.unl.edu, verified 28 Feb. 2006) located in Lincoln, NE, the model contains an automatic conversion utility to convert the weather data downloaded from the HPRCC to the format and units required by the model. Weather data from other sources can also be prepared easily in a spreadsheet program following the instructions in the program's user guide under the help button. Because errors and missing data

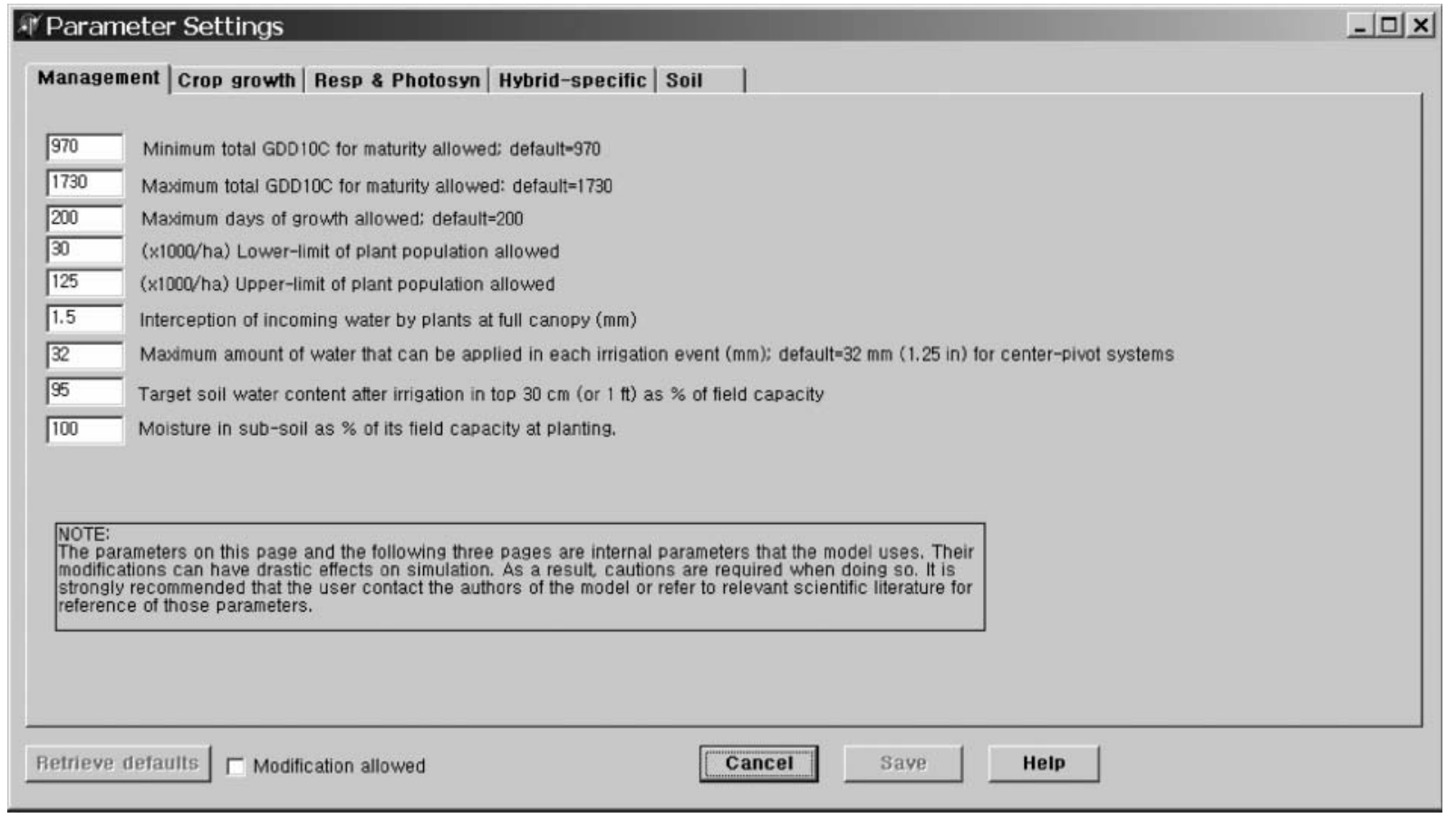

Fig. 3. Access to internal parameters in the Hybrid-Maize model software. Parameters are grouped on four pages: Management, Crop growth, Resp \& Photosyn (for respiration and photosynthesis), Hybrid-specific parameters for the relationship between relative maturity (CRM) to total growing degree days (GDD), and Soil. All values can be changed by the user or restored to their original default values by clicking on the 'Retrieve defaults' button at lower left. 
are common in large weather datasets, Hybrid-Maize has a utility for identifying outlier values in the daily weather data entries and can replace missing data. Suspicious or missing data are reported and recorded in a text file so that the user can easily locate file errors to correct errant values.

\section{Simulation Modes}

Three simulation modes are available: (1) 'Long-term runs' using a selected set or all years of available historical site weather data, (2) 'Single year' simulations with or without a long-term simulation run for comparison, and (3) 'Current season prediction' to the end of the growing season.

The 'Long-term runs' mode (1) is used for estimating the long-term site yield potential and its variability under an optimal moisture regime without water stress, or for estimating the attainable water-limited yield potential under rainfed conditions. For both cases, yield potential can be evaluated with respect to different hybrid maturities, planting dates, and plant populations. This mode can be used to estimate the impact on yield from changes to one or more of these management practices. While the default mode simulates across all years, the user can also select specific periods within historical weather database. All simulations results are ranked by predicted grain yield and a detailed summary of results are reported for five rank years (i.e., the years with the highest, 75 th percentile, median, 25 th percentile, and worst yield). In addition, predicted mean values and coefficients of variation (CV) are computed for key model outputs. Overall probability of frost damage during grain filling is also reported for the time series in the long-term simulation mode. For each rank year, detailed outputs are reported for other parameters such as stover yield and harvest index, days to silking and maturity, total duration of vegetative and grain-filling periods, total cumulative solar radiation, mean maximum, minimum and average daily temperature during the vegetative and grain-filling stages, and total precipitation during the growing season. To investigate site yield potential and yield variability using the long-term run mode, it is recommended that the historical weather file includes at least $10 \mathrm{yr}$ of data.

Single year without long-term runs mode (2) is primarily used to evaluate the influence of management or climate factors on yield in an individual year, or to estimate the size of the exploitable yield gap by comparing simulated yield potential with actual measured yields. Typically, this type of simulation constitutes a post-hoc analysis of a past growing season. Up to six individual runs can be made sequentially and their results can be compared, both numerically and graphically on the output pages. Single year with long-term runs mode is useful for comparing a given year with the long-term site yield potential as simulated for all other years in the weather database for that site. In this mode, the user can investigate why the yield potential in a given year was above or below average and which climatic factors may have contributed to observed differences across years. All simulations are ranked by predicted grain yield and detailed summary results are reported for the chosen year as well as the years that represented the highest, 75th percentile, median, 25th percentile, and worst yield within the population of years in the weather database.

'Current season prediction' mode (3) allows in-season (or real-time) assessment of corn growth up to the current date based on the actual weather data up to that point in time, followed by prediction of growth and final yield thereafter based on historical weather data for the remainder of the growing season (Fig. 4). Similar to the 'Long-term runs' mode, predictions are ranked according to grain yield and results are shown for the scenarios with the highest, 75th percentile, median, 25 th percentile, and worst yields.

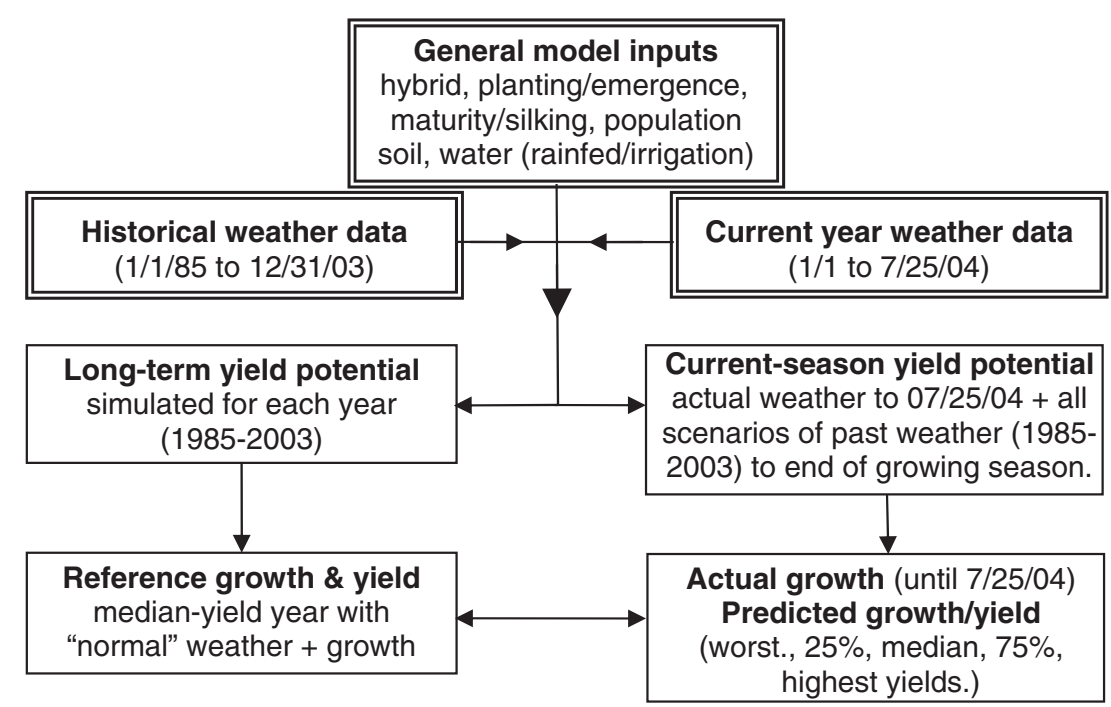

Fig. 4. Approach used for in-season (real-time) yield prediction in the Hybrid-Maize model. In this example, a real-time simulation is conducted for 25 July 2004, using weather data for the period January 1985 to 25 July 2004. Input data has double lined borders and model output has single lined borders. 


\section{Crop Management and Hybrid-Specific Inputs}

Other input settings include start day (either planting or emergence date), crop maturity, plant population, water regime, and soil properties (in case of simulations under water-limited conditions). A simulation can begin either from planting date or emergence date (Fig. 1). If start day is planting date, planting depth must be specified so that Hybrid-Maize can simulate emergence date.

Maturity can be set as either the actual observed date of maturity (e.g., in 'single-run' mode) or as total growing degree days (GDD) from emergence to physiological maturity (blacklayer) of the hybrid (e.g., in 'long-term runs' and 'current-season prediction' modes). Most commercial seed companies publish GDD values for their hybrids. The base temperature for GDD is $10^{\circ} \mathrm{C}$ (metric system) or $50^{\circ} \mathrm{F}$ (English system). If information on GDD values to physiological maturity is not available for a hybrid, users can enter a comparative relative maturity (CRM) in days as an alternative. In such cases, the model uses seed brand-specific or generic relationships between GDD and CRM to estimate GDD for reaching maturity.

Accurate estimation of silking date is crucial for simulating grain yield because it represents the transition from vegetative to reproductive growth stages, and grain yield is extremely sensitive to the duration of the grainfilling phase (Yang et al., 2004a). The software offers the option of entering either the observed date of silking (e.g., in 'single run' mode) or GDD from emergence to silking. If neither is known, the program will estimate the date of silking using an internal algorithm based on seed brand specific or generic relationships between GDD to physiological maturity and GDD to silking (Yang et al., 2004a).

Setting plant population is straightforward. For settings of both total GDD and plant population, there are default minimum and maximum limits for these values and a warning message will pop up if the settings are outside the range for which Hybrid Maize has been validated. These limits, however, may be modified by the user through the 'Parameter settings' menu.

Optimal or water-limited growth simulation can be accomplished by choosing either 'Optimal' or 'Rainfed/ Irrigated' modes (Fig. 2). If 'Optimal' is selected, there is no need to enter soil properties (the whole soil panel is grayed out), as soil is assumed to provide optimal water supply. However, if the option 'Estimate irrigation water requirement' is selected, soil physical properties must be entered as for rainfed and irrigated crop simulations. Required soil properties include estimated initial gravimetric moisture content of topsoil (i.e., 0-30 cm), maximum rooting depth, bulk density, and textural class of topsoil and subsoil. When 'Rainfed/Irrigated' is selected, an irrigation schedule can also be specified (dates and amount); if it is left blank the model will assume rainfed conditions. Different irrigation strategies can be explored by changing irrigation times and amounts and evaluating the impact on yield. The irrigation schedule can be saved/retrieved along with other model settings for use in future simulations.

\section{APPLICATIONS}

\section{Example 1: Analyzing Site Yield Potential under Optimal Conditions}

This example illustrates how Hybrid-Maize can be used to explore interactions of planting date and hybrid maturity and their influence on yield potential. This simulation is based on our experience in a research project that seeks to better understand the genetic and environmental determinants of maize yield potential. The research site is located in southeast Nebraska at the University of Nebraska, Lincoln $\left(40.82^{\circ} \mathrm{N}, 96.65^{\circ} \mathrm{W}\right)$ where irrigated corn is grown on a deep alluvial soil (fine-silty, mixed, superactive, mesic Cumulic Hapludolls) with optimal nutrient supply and pest management. The current recommendations for southeast Nebraska is to plant between 25 April and 5 May at 0.76-m row spacing and a final population of 79000 plants $\mathrm{ha}^{-1}$. Common hybrids grown in this environment require 1500 GDD (base = $10^{\circ} \mathrm{C}$ or $2700 \mathrm{GDD}$ base $=50^{\circ} \mathrm{F}$ ) to reach maturity.

Input settings (in metric units) for this exercise were: Mode = long-term run from 1986 to 2004, start from planting on 1 May with a planting depth of $4 \mathrm{~cm}$, maturity = total GDD 1500 (CRM of about $112 \mathrm{~d}$ ), population $=79000 \mathrm{ha}^{-1}$, water $=$ optimal. The results screen from this simulation provides a summary of the outputs and is shown as "simulation 1 " in the upper section of Fig. 5.

The model predicted an average grain yield potential of $13.8 \mathrm{Mg} \mathrm{ha}^{-1}$ (at $15.5 \%$ moisture content) with a range of 11.8 to $16.2 \mathrm{Mg} \mathrm{ha}^{-1}$ during the 19 -yr period for which weather data are available. Risk of frost occurrence during grain filling was zero. Note that the average temperature during grain filling ( $\mathrm{rTmean}$ ) ranged from 24.4 to $25.8^{\circ} \mathrm{C}$ for $50 \%$ of $19 \mathrm{yr}(25-75 \%$ percentile range). The lowest yield occurred in 1995 when rTmean was high $\left(26.6^{\circ} \mathrm{C}\right)$. In contrast, the highest yield occurred in 1994 when rTmean was only $23.3^{\circ} \mathrm{C}$, resulting in a long grain-filling period (rDays $=56 \mathrm{~d}$ ) and a total growth duration $(\mathrm{V}+\mathrm{R})$ of $112 \mathrm{~d}$.

Upon analysis of these simulated data, the question arises as to whether yield potential in most years could be increased by shifting grain filling later into September when nighttime temperatures begin to cool, but without significantly increasing the risk of frost. This could be accomplished by planting at a later date, choosing a longer maturity hybrid, or a combination of both. We first explored a later planting date (10 May) while keeping the same hybrid (1500 GDD), which would, on average, initiate grain filling at a later date. Simulation 2 in Fig. 5 shows the results from this change. The model predicted a long-term average yield potential of $14.2 \mathrm{Mg}$ $\mathrm{ha}^{-1}$, ranging from 11.9 to $17.3 \mathrm{Mg} \mathrm{ha}^{-1}$ during the $19-\mathrm{yr}$ period in the weather file. Risk of frost occurrence during grain filling was still zero. Overall, planting the same hybrid $10 \mathrm{~d}$ later predicted a slight increase in yield potential, which resulted from a small increase in the grain-filling period (long-term average rDays was 53 for the 10 May planting vs. 51 for the 1 May planting).

The effect of planting a longer maturity hybrid was evaluated in simulation 3 while keeping planting date 
Simulation run \#1

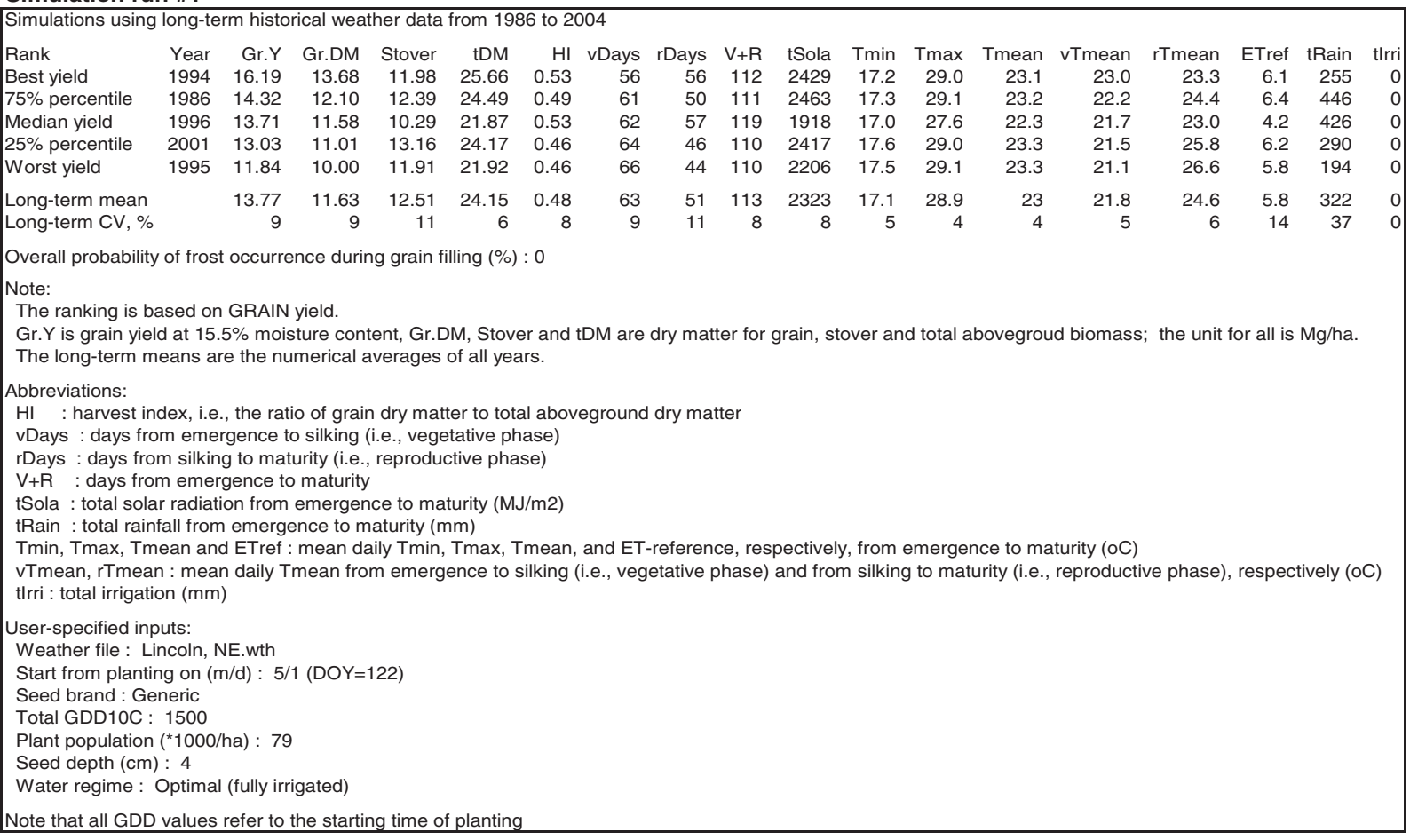

\section{Simulation run \#2}

\begin{tabular}{|c|c|c|c|c|c|c|c|c|c|c|c|c|c|c|c|c|c|c|}
\hline \multicolumn{19}{|c|}{ Simulations using long-term historical weather data from 1986 to 2004} \\
\hline Rank & Year & Gr.Y & Gr.DM & Stover & tDM & $\mathrm{HI}$ & vDays & rDays & $V+R$ & tSola & Tmin & Tmax & Tmean & vTmean & rTmean & ETref & tRain & tIrri \\
\hline Best yield & 1992 & 17.32 & 14.63 & 11.55 & 26.19 & 0.56 & 69 & 72 & 141 & 2592 & 14.2 & 26.6 & 20.4 & 20.5 & 20.3 & 4.6 & 416 & 0 \\
\hline $75 \%$ percentile & 1996 & 14.87 & 12.56 & 10.12 & 22.68 & 0.55 & 61 & 62 & 123 & 2003 & 16.6 & 27.2 & 21.9 & 21.9 & 21.9 & 4.2 & 436 & 0 \\
\hline Median yield & 1999 & 14.17 & 11.97 & 10.67 & 22.64 & 0.53 & 61 & 49 & 110 & 2134 & 17.9 & 28.8 & 23.4 & 22.1 & 25.0 & 5.5 & 333 & 0 \\
\hline $25 \%$ percentile & 1990 & 13.61 & 11.50 & 13.55 & 25.05 & 0.46 & 53 & 50 & 103 & 2283 & 18.4 & 30.0 & 24.2 & 23.7 & 24.7 & 6.2 & 432 & 0 \\
\hline Worst yield & 1988 & 11.87 & 10.03 & 15.88 & 25.91 & 0.39 & 50 & 42 & 92 & 2221 & 19.5 & 32.0 & 25.8 & 24.7 & 27.0 & 7.4 & 135 & 0 \\
\hline Long-term mean & & 14.22 & 12.02 & 11.97 & 23.99 & 0.5 & 57 & 53 & 110 & 2236 & 17.6 & 29.3 & 23.5 & 22.9 & 24.2 & 5.8 & 318 & 0 \\
\hline Long-term CV, \% & & 9 & 9 & 13 & 7 & 9 & 10 & 14 & 10 & 8 & 7 & 5 & 6 & 6 & 7 & 14 & 35 & 0 \\
\hline
\end{tabular}

\section{Simulation run \#3}

\begin{tabular}{|c|c|c|c|c|c|c|c|c|c|c|c|c|c|c|c|c|c|c|}
\hline \multicolumn{19}{|c|}{ Simulations using long-term historical weather data from 1986 to 2004} \\
\hline Rank & Year & Gr.Y & Gr.DM & Stover & tDM & $\mathrm{HI}$ & vDays & rDays & $V+R$ & tSola & Tmin & Tmax & Tmean & vTmean & rTmean & ETref & tRain & tIrri \\
\hline Best yield & 1992 & 18.16 & 15.35 & 12.89 & 28.24 & 0.54 & 75 & 76 & 151 & 2817 & 14.1 & 26.6 & 20.3 & 20.2 & 20.4 & 4.8 & 449 & 0 \\
\hline $75 \%$ percentile & 1986 & 16.72 & 14.13 & 12.78 & 26.91 & 0.52 & 63 & 57 & 120 & 2644 & 17.1 & 28.8 & 23.0 & 22.2 & 23.8 & 6.3 & 452 & 0 \\
\hline Median yield & 2001 & 15.25 & 12.89 & 13.33 & 26.22 & 0.49 & 66 & 51 & 117 & 2566 & 17.6 & 29.1 & 23.3 & 21.5 & 25.7 & 6.2 & 295 & 0 \\
\hline $25 \%$ percentile & 1993 & 15.00 & 12.67 & 11.08 & 23.76 & 0.53 & 72 & 64 & 136 & 2353 & 15.8 & 27.1 & 21.4 & 20.7 & 22.2 & 4.7 & 624 & 0 \\
\hline Worst yield & 1988 & 12.71 & 10.74 & 17.42 & 28.16 & 0.38 & 55 & 48 & 103 & 2512 & 18.6 & 31.4 & 25.0 & 23.8 & 26.4 & 7.5 & 142 & 0 \\
\hline \multirow{2}{*}{\multicolumn{2}{|c|}{$\begin{array}{l}\text { Long-term mean } \\
\text { Long-term CV, \% }\end{array}$}} & 15.48 & 13.08 & 12.64 & 25.72 & 0.51 & 65 & 57 & 121 & 2462 & 17 & 28.8 & 22.9 & 21.9 & 24.1 & 5.8 & 351 & 0 \\
\hline & & 9 & 9 & 11 & 6 & 8 & 9 & 14 & 10 & 7 & 7 & 4 & 5 & 5 & 7 & 14 & 34 & 0 \\
\hline
\end{tabular}

Overall probability of frost occurrence during grain filling $(\%): 0$

Simulation run \#4

\begin{tabular}{|c|c|c|c|c|c|c|c|c|c|c|c|c|c|c|c|c|c|c|}
\hline \multicolumn{19}{|c|}{ Simulations using long-term historical weather data from 1986 to 2004} \\
\hline Rank & Year & Gr.Y & Gr.DM & Stover & tDM & $\mathrm{HI}$ & vDays & rDays & $V+R$ & tSola & Tmin & Tmax & Tmean & vTmean & rTmean & ETref & tRain & tIrri \\
\hline Best yield & 1996 & 17.82 & 15.05 & 10.59 & 25.64 & 0.59 & 63 & 79 & 142 & 2307 & 15.6 & 26.3 & 21.0 & 22.1 & 20.0 & 4.1 & 480 & 0 \\
\hline $75 \%$ percentile & 1989 & 17.44 & 14.74 & 12.36 & 27.10 & 0.54 & 59 & 65 & 124 & 2634 & 16.3 & 28.8 & 22.6 & 23.0 & 22.2 & 5.8 & 472 & 0 \\
\hline Median yield & 2003 & 15.80 & 13.36 & 12.29 & 25.65 & 0.52 & 62 & 56 & 118 & 2464 & 16.7 & 29.5 & 23.1 & 22.3 & 24.0 & 6.0 & 304 & 0 \\
\hline $25 \%$ percentile & 1998 & 14.96 & 12.64 & 11.55 & 24.19 & 0.52 & 61 & 54 & 115 & 2178 & 18.1 & 29.0 & 23.6 & 22.6 & 24.6 & 5.0 & 437 & 0 \\
\hline Worst yield & 1995 & 13.70 & 11.57 & 11.71 & 23.29 & 0.50 & 62 & 52 & 114 & 2242 & 17.9 & 29.4 & 23.6 & 22.4 & 25.2 & 5.7 & 209 & 0 \\
\hline \multirow{2}{*}{\multicolumn{2}{|c|}{$\begin{array}{l}\text { Long-term mean } \\
\text { Long-term CV, \% }\end{array}$}} & 15.87 & 13.41 & 12.26 & 25.67 & 0.52 & 60 & 59 & 119 & 2382 & 17.3 & 29.1 & 23.2 & 22.9 & 23.6 & 5.7 & 346 & 0 \\
\hline & & 9 & 9 & 12 & 5 & 9 & 9 & 16 & 12 & 7 & 9 & 6 & 7 & 5 & 9 & 14 & 34 & 0 \\
\hline
\end{tabular}

Fig. 5. Screenshots of the summary 'Results' pages from four simulation runs of long-term yield potential at Lincoln, NE using different combinations of planting date and hybrid maturity: Simulation run 1, planting on 1 May with 1500 growing degree days (GDD) hybrid; Simulation run 2, planting on 15 May with 1500 GDD hybrid; Simulation run 3, planting on 1 May with 1590 GDD hybrid; Simulation run 4, planting on 15 May with 1590 GDD hybrid. Other input settings are shown in the top screen of Fig. 1.

and other input settings the same as in simulation 1 . Because hybrids with a relative maturity rating of about $119 \mathrm{~d}$ are available for this environment, the GDD to maturity was set at 1590 . The model predicted an average yield potential of about $15.5 \mathrm{Mg} \mathrm{ha}^{-1}$, with a range of 12.7 to $18.2 \mathrm{Mg} \mathrm{ha}^{-1}$ (simulation 3 in Fig. 5). This represents a $12 \%$ increase compared to planting a 112-d hybrid with total GDD of 1500 . With the longer maturity hybrid the average length of grain filling increased from 51 to $57 \mathrm{~d}$, which is the primary reason for 
the increased yield compared to simulations with the earlier maturing hybrid.

The results from simulations 1 to 3 raise the issue of whether yield potential could be further increased by use of a longer maturity hybrid in combination with a later planting date. A fourth simulation was run with the same settings as in simulation 3 but with a later planting on 10 May. The results from this combination further increased the predicted average yield potential to $15.9 \mathrm{Mg} \mathrm{ha}{ }^{-1}$ and also narrowed the overall range to 13.7 to $17.8 \mathrm{Mg} \mathrm{ha}^{-1}$, which indicates greater yield stability in addition to higher mean yield (simulation 4 in Fig. 5). The average length of the grain-filling period increased to $59 \mathrm{~d}$ and there is only small $(5 \%)$ risk of frost occurrence before the crop reaches maturity under this scenario.

While additional combinations of planting dates and hybrid maturity can be explored, other factors must be considered in selecting the most appropriate combination. For example, the model suggests that planting the 119-d hybrid on 30 May may further increase yield potential at Lincoln to an average of $17.1 \mathrm{Mg} \mathrm{ha}^{-1}$, but at the increased risk of frost risk (17\%). The logistics of harvesting, harvest losses, and cost of grain drying due to much later maturity in mid-October must also be considered.

In summary, simple changes in hybrid selection and planting date resulted in substantial increases in predicted yield potential with greater yield stability and relatively low risk of frost compared to current recommended practices for southeast Nebraska. This modified management regime achieves higher yields through a longer grain-filling period as a result of delaying the grain-filling period into late September when night temperatures are much cooler than late August and early September. It should be noted, however, that mean temperatures at this site within the City of Lincoln are warmer than in surrounding rural environments and therefore these results may not be widely applicable to the surrounding region. However, the exercise demonstrates the use of Hybrid-Maize to evaluate changes in management. It is also noteworthy that recent field studies at the Lincoln research site have confirmed the predicted improvements in yield potential from later planting with a longer maturity hybrid (Dobermann et al., 2005).

\section{Example 2: Estimating Water Requirements for Optimal Yields}

Another potential model application is to estimate crop water requirements and irrigation timing. As an example, we will simulate irrigated corn in southwest Nebraska. This is an area with high yield potential (elevation about $1000 \mathrm{~m}$, semiarid climate with high solar radiation), provided that crops are fully irrigated with optimal nutrient supply and pest management. Rainfall is highly variable from year to year and averages about $500 \mathrm{~mm}$ annually, with about half coming during the growing season. Standard practices for irrigated corn are to plant around 1 May at 0.76-m row spacing and a final population of 74000 plants $\mathrm{ha}^{-1}$. Common hybrids in this area require total GDD of 1440. A weather station representing this area is located at Champion, $\mathrm{NE}\left(40.40^{\circ} \mathrm{N}, 101.72^{\circ} \mathrm{W}\right)$ with daily climate data available for the 1982 to 2003 period. The site simulated is a gently sloping field with a deep, welldrained, fine-loamy soil. Rooting depth is not limited by a hardpan or compacted layer, and general soil quality is good.

A long-term simulation run was performed for this site for the period of 1982 to 2003 using the 'Optimal' mode. The average yield potential was $15.9 \mathrm{Mg} \mathrm{ha}^{-1}$ but with a wide range (12.0-20.5 $\mathrm{Mg} \mathrm{ha}^{-1}$ ) and a $27 \%$ probability of premature frost. The grain-filling period is relatively long (average of $67 \mathrm{~d}$ ) due to cooler average temperatures than at Lincoln; nighttime temperatures during grain filling are considerably cooler than at Lincoln (rTmean averaged $21^{\circ} \mathrm{C}$ ). Given these results, there is less potential to extend the growing season because of increased risk of yield loss from frost damage. The key production constraint is water availability for irrigation in this semiarid environment.

To illustrate the severity of water stress in this region, a run was made using the same settings as above but for rainfed conditions. Settings for soil properties were moisture content of topsoil $=25 \%(\mathrm{w} / \mathrm{w})$ at planting, maximum rooting depth $=1 \mathrm{~m}$, bulk density and texture of topsoil and subsoil were $1.3 \mathrm{~g} \mathrm{~cm}^{-3}$ and loam, and $1.4 \mathrm{~g} \mathrm{~cm}^{-3}$ and loam, respectively. Without irrigation, attainable yield averaged $9.1 \mathrm{Mg} \mathrm{ha}^{-1}$ with $264 \mathrm{~mm}$ of rainfall during the growing season, but can be as low as $4.4 \mathrm{Mg} \mathrm{ha}^{-1}$ with $105 \mathrm{~mm}$ of rainfall with poor distribution, or as high as $17.5 \mathrm{Mg} \mathrm{ha}^{-1}$ with $522 \mathrm{~mm}$ of rainfall with good distribution throughout the growing season.

Irrigation is needed at critical growth stages to overcome the water deficit that occurs in this region. To estimate the water requirement for maintaining adequate water supply throughout the crop growth period, we assumed that the maximum amount of deliverable water per (sprinkler) irrigation event was $32 \mathrm{~mm}$ (through 'Settings, Parameter settings' in the menu). The summary of simulation output is similar to Fig. 5, but an additional column reports the total irrigation water requirement (not shown). On average, $296 \mathrm{~mm}$ of additional water (11.7 inches) is required to achieve stress-free growth, but the water requirement varies from about 226 (1999, the best year) to $356 \mathrm{~mm}$ (1997, $75 \%$ percentile of grain yield). The amount and predicted timing of irrigation for the year of median yield (1991) are shown in Fig. 6, along with daily rainfall and soil moisture dynamics in three layers (i.e., 0-30; $30-60$; and $<60 \mathrm{~cm}$ ). Other years can be selected for display from the dropdown list, and numerical outputs are also available on the 'Results' page.

The actual amount of irrigation required would also depend on the efficiency of the irrigation system because the Hybrid-Maize assumes that all water that reaches the soil surface enters the soil water pool. It does not account for runoff or evaporation, or non-uniformity of irrigation. The model does account for a small amount of 


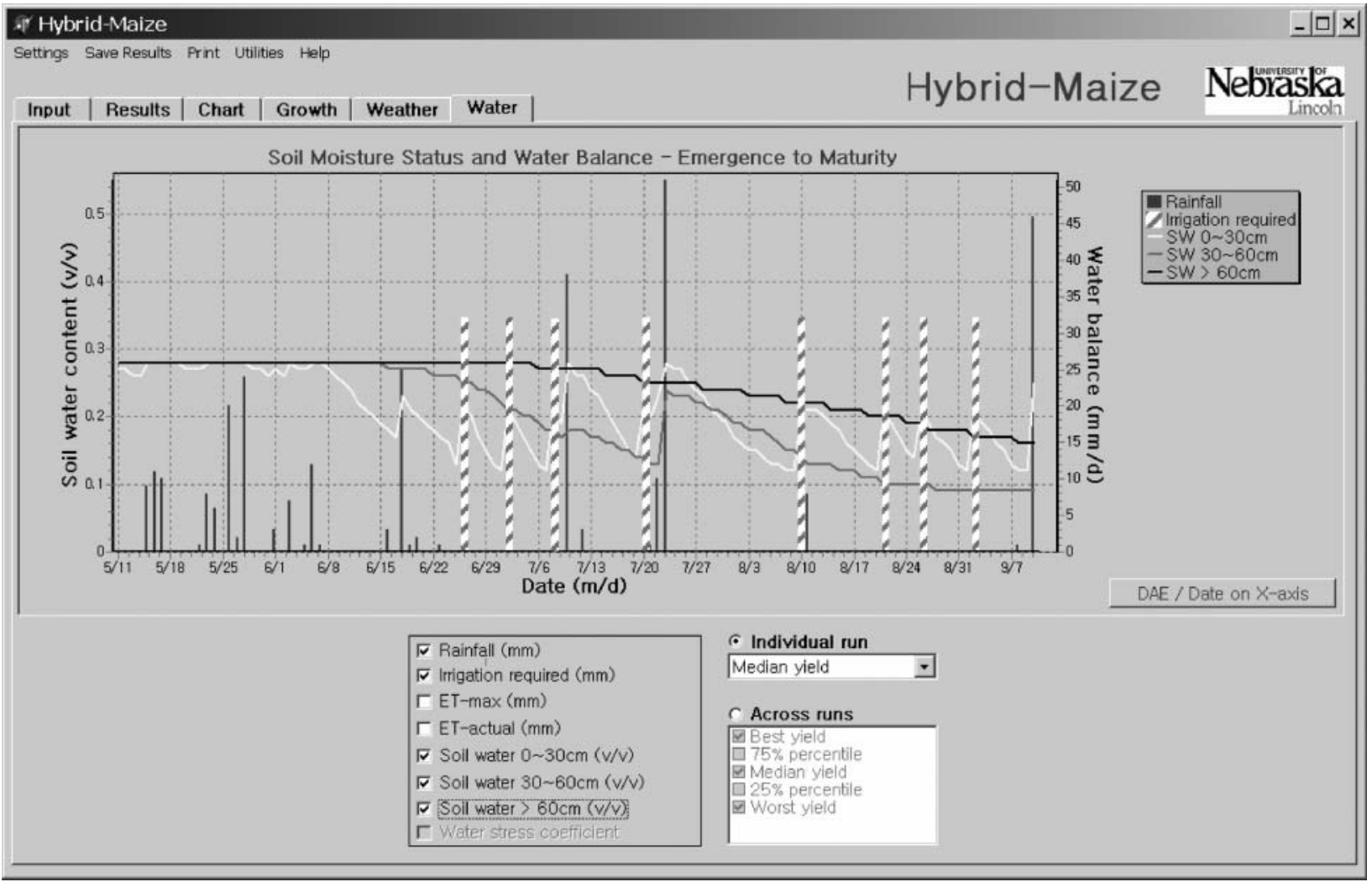

Fig. 6. Screenshot of the Hybrid-Maize 'Water' page showing predictions of irrigation water requirement (striped bars) for the year of median yield in the simulation described in the text. The darker bars are rainfall. Total irrigation and rainfall amounts are given on the 'Results' page (not shown).

irrigation water loss that is adsorbed on leaf surfaces. The default setting under the 'Management' tab in 'Parameter settings' is $1.5 \mathrm{~mm}$ of intercepted water per irrigation event. The remainder of the applied water is assumed to replenish the soil water pool.

\section{Example 3: Real-time Crop Growth Simulation and Yield Forecast}

Corn yield potential varies considerably from year to year in the same field as a result of the combined effects of variation in solar radiation and temperature in irrigated systems as well as rainfall in rainfed systems. In-season crop model predictions can be used to guide management and marketing decisions, along with other sources of information, common sense, and experience (Dobermann and Yang, 2004). The 'Current season prediction' mode in Hybrid-Maize allows the user to simulate "real-time" crop growth during a growing season up to the date of the simulation run. To interpret real-time simulations, however, we recommend that the weather file contain at least $10 \mathrm{yr}$ of representative historical climate data for the site (or a nearby weather station) in addition to weather data for the current year.

This real-time simulation example involves 2003 data from two fields in eastern Nebraska: one from Lincoln (irrigated) and the other from Mead (rainfed). Yield forecasts were made every $5 \mathrm{~d}$, beginning shortly after planting (Fig. 7). At each forecasting date, actual weather data were used in Hybrid-Maize to simulate growth until that date. From that point forward to maturity, the model used historical weather records to simulate possible growth scenarios for the remainder of the season.

At Lincoln, the crop was grown under a management regime to achieve yields that approach the yield potential ceiling with full irrigation, optimal nutrient supply, and a density of 87000 plants ha ${ }^{-1}$. Early in the season, yield forecasts mainly relied on historical weather data to complete the simulation, and as a result, the median predicted yield was close to the long-term median yield potential of about $17 \mathrm{Mg} \mathrm{ha}^{-1}$ (Fig. 7a, lower dashed line). As the season progressed and more actual weather data were used, the range of potential yield outcomes began to converge after silking. By midAugust, the model predicted a $75 \%$ probability that the final grain yield would be equal to or greater than the long-term average with a range of 17 to $19 \mathrm{Mg} \mathrm{ha}^{-1}$.

At Mead, the crop was grown under rainfed conditions in a production field at 59000 plants $\mathrm{ha}^{-1}$. Predicted median yield was close to the long-term median water-limited yield potential early in the season (Fig. 7b, upper dashed line), but by silking predicted yields began to fall because of less than normal rainfall. Predicted water-limited yield potential continued to decline throughout the remainder of the growing season because of continued drought. By the end of August the range of predicted outcomes indicated a range in final yield of from 6 to $9 \mathrm{Mg} \mathrm{ha}^{-1}$, which is 46 to $69 \%$ of the long-term median rainfed yield potential at this site. The final measured grain yield of $8.0 \mathrm{Mg} \mathrm{ha}^{-1}$ confirmed this prediction. 

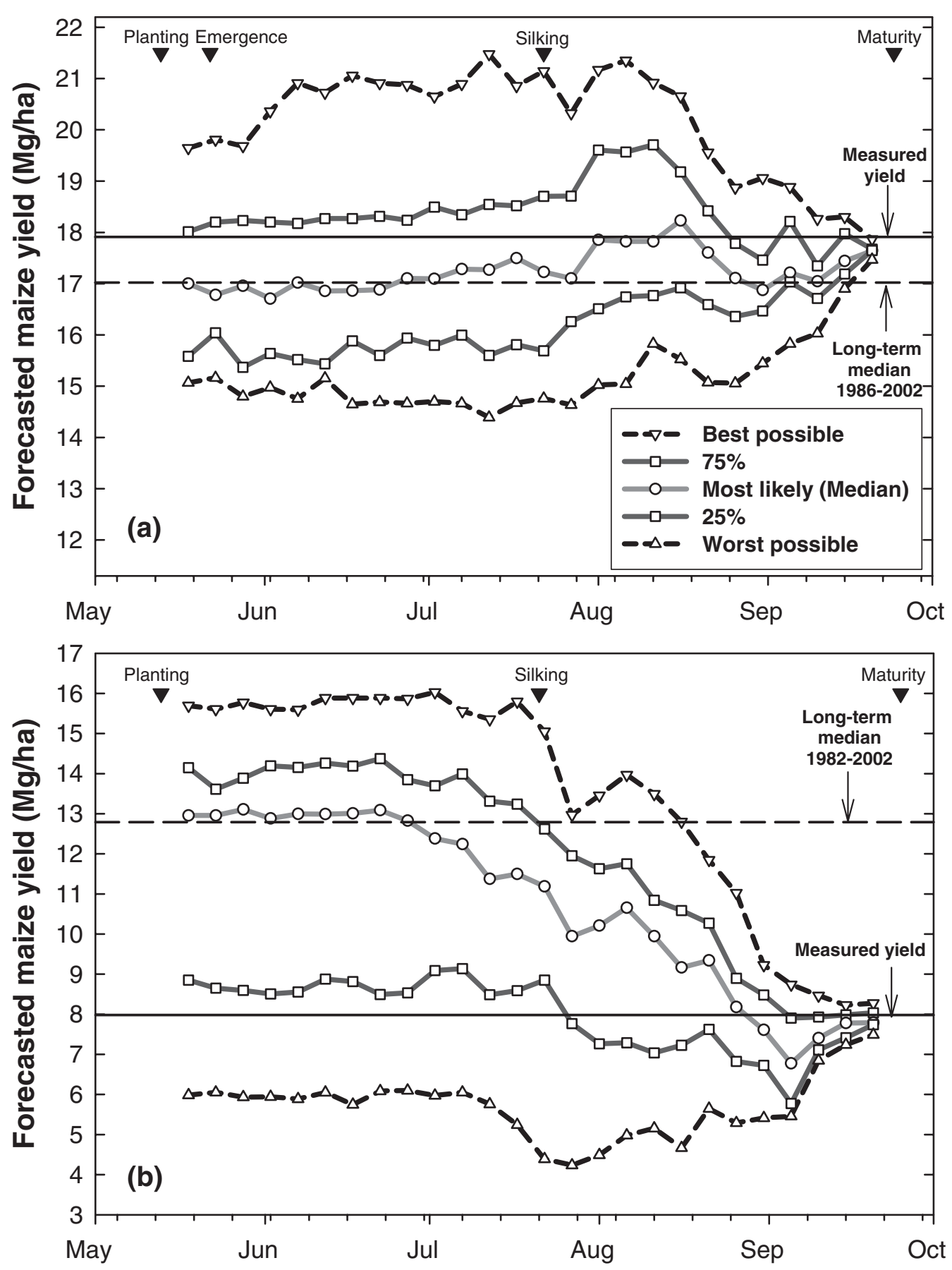

Date of yield forecast

Fig. 7. In-season yield forecasting in 5-d intervals (points) for two fields in Nebraska in 2003: (a) Irrigated maize at Lincoln, (b) Rainfed maize grown at Mead. Dates of planting, silking and maturity are marked by the arrows in the graphs, and the long-term median yields and measured final yields are shown as horizontal lines. This is the resultant output from the model iterations illustrated in Fig. 4 and is displayed in the "Yield Trend" page.

\section{DISCUSSION AND CONCLUSIONS}

The Hybrid-Maize model was found to be more robust than other existing corn models for simulating growth and yield under optimal growth conditions (Yang et al., 2004a). Moreover, Hybrid-Maize software offers an intuitive graphic user interface for input and output settings with features and auxiliary functions that help non-modelers use the Hybrid-Maize model as a tool for crop management, extension education, teaching, and research. The comprehensive help system provides instructions and background information for users at all levels. At the same time, the transparency in internal parameters and the flexibility in their settings, along with complete documentation of the model's formulation, make the model easy to work with for testing, validation, and further refinement for local conditions. 
So far the Hybrid-Maize model has mainly been validated with plant densities of 60000 to 100000 plants $\mathrm{ha}^{-1}$ and commercial hybrids that predominantly have a single ear with relatively little prolificacy. The model performance needs further evaluation before it can be used with confidence outside this range in plant population. The formulation proposed recently by Ritchie and Alagarswamy (2003) for predicting yield components provides a promising avenue to potentially improve model performance across a wider range of populations. Although Hybrid-Maize simulates corn growth and yields under optimal water regime as well as water-limited conditions, most of the model validation so far has been conducted under optimal water conditions in the western and central U.S. Corn Belt. Therefore, simulation results under water-limited conditions must be interpreted and used with caution, particularly in areas that are prone to severe drought and heat stress at key growth stages.

Sensitivity analysis in Yang et al. (2004a) indicates that model results are sensitive to dates of critical growth stages, which can either be provided as an input to the model or predicted by the model. The dates of silking and physiological maturity as defined by Ritchie et al. (1992) are particularly sensitive. Those dates should only be entered if accurate measurements have been taken. Otherwise, the model appears to do a reasonable job of estimating the date of these events. Simulated yield can be seriously affected by entering wrong silking or maturity dates, or an incorrect value for GDD to maturity for a commercial hybrid. When in doubt, use the GDD option to let the model predict silking and maturity dates based on the total GDD to maturity for the hybrid used, and be sure to check that the correct GDD value has been entered. In some unusual cases, however, this approach may lead to an unrealistically long predicted growing season when a full-season hybrid is planted late and cool weather predominates during last half of grain filling. There is a need to verify predicted maturity dates with observations, and to use common sense about sufficient time for grain dry down to allow timely harvest and to avoid additional grain drying costs.

As the model is based on mechanistic descriptions of corn growth and development, it is expected to perform well in a wide range of environments. Nevertheless, caution should be exercised when using Hybrid-Maize outside the U.S. Corn Belt as this may require changes in some of the default model parameters. In exploring site yield potential with the model, it is important to note that yield potential can only be achieved under growth conditions that are 'ideal' with regard to both crop and soil management. Reasonable soil quality is also required. Although it is theoretically possible to overcome shallow soil depth or a hardpan that restricts root growth by employing more precise management of nutrients and irrigation, it is generally not practical or profitable to do so at a production scale. Likewise, some soil constraints, such as salinity or soil acidity, reduce crop growth directly and therefore make it impossible to achieve yield levels that approach the genetic yield potential of a given hybrid even with optimal management of water, nutrients, and pests. Therefore, in inter- preting investigations of site yield potential, model users must be aware of limitations to crop growth that are not considered in the model, such as soil compaction, shallow soil depth, sandy soil texture, or soil acidity or salinity. In general, investigation of site yield potential using Hybrid-Maize is most appropriate for fields in which soil quality is relatively good and there are no obvious constraints to crop growth.

As with all simulation models, Hybrid-Maize still represents a simplification of the 'real-world' system and, as such, model simulations may differ from actual outcomes. There are uncertainties or weaknesses in HybridMaize that will have to be addressed in future research and subsequent model releases. They include:

1. Underprediction of maximum leaf area index (LAI) at high plant density $\left(>90000 \mathrm{ha}^{-1}\right)$ under optimal growth conditions, which was also a common weakness of other corn models (Yang et al., 2004a). This suggests that the description of leaf area expansion in the model is still not sufficiently robust for high plant populations. As larger LAI implies greater $\mathrm{C}$ and $\mathrm{N}$ construction and maintenance costs as well as larger $\mathrm{N}$ storage capacity, underprediction of LAI could potentially affect plant $\mathrm{C}$ balance, late-stage leaf senescence dynamics and ultimately grain yield.

2. The model has primarily been tested with plant populations in the range of 60000 to 100000 plants $\mathrm{ha}^{-1}$. An empirical equation derived for this range is used to describe the effect of plant density on the rate of grain filling (Yang et al., 2004a). The model should not be used outside this range without further verification. A recent review of corn yield in relation to population suggests that high population could induce several yield reducing effects (e.g., increased interval of silking-to-pollination), especially under water-limited growth conditions, and actual crop response to plant population may also vary among hybrids (Tokatlidis and Koutroubas, 2004).

3 . The model does not account for effects of varying row spacing on growth and yield. All development and validation research was conducted with maize planted at $0.76-\mathrm{m}$ row spacing.

4. The coefficients for maintenance respiration of different organs are largely unverified under field conditions. Likewise the negative effects on pollination from high temperatures during the silking window are not considered. These effects need further research and refinement in the model.

5. In stress environments, underprediction of LAI is likely to have a larger impact on simulated yield than in favorable environments. In Hybrid-Maize, leaf area is simulated by a discrete set of equations as in the original CERES-Maize model: one for the period before tassel initiation and another for the period thereafter to silking. This approach provides few opportunities to account for genotypic differences or to simulate the interactive effects of stresses on leaf expansion and senescence (Lizaso et al., 2003). Such interactions were identified as 
constraints to robust prediction of maize growth under stressed conditions (Carberry et al., 1989; Keating et al., 1992). We therefore suspect that the functions of leaf expansion during rapid vegetative growth will need improvement in the model if used in stress environments. While Lizaso et al. (2003) have proposed a more detailed, hybridspecific leaf area model for maize, it requires three additional hybrid-specific input parameters related to leaf growth and expansion.

Current and future work to improve the HybridMaize model focuses on (i) addressing some of the uncertainties listed above, especially with regard to crop water stress; (ii) adding a module to help estimate N, P, and $\mathrm{K}$ fertilizer requirements; and (iii) adding a module to predict grain moisture content during the dry-down period to harvestable maturity. In addition, we continue to test and validate the model across a wider range of production environments and management levels. More information about the model's development, applications and information update is available at a dedicated website at www.hybridmaize.unl.edu. The model software is available for online purchase at $\mathrm{http}: / /$ estore.adec. edu (verified 3 Mar. 2006).

\section{ACKNOWLEDGMENTS}

This work was partially supported by the Foundation for Agronomic Research, the Fluid Fertilizer Foundation, DOEOffice of Science (BER: Grant nos. DE-FG03-00ER62996 and DE-FG02-03ER63639), DOE-EPSCoR (Grant no. DE-FG0200ER45827), the Cooperative State Research, Education, and Extension Service, U.S. Department of Agriculture (Agreement no. 2001-38700-11092), and the University of Nebraska Agricultural Research Division, Journal Series no. 14546.

\section{REFERENCES}

Brisson, N., C. Gary, E. Justes, R. Roche, B. Mary, D. Ripoche, D. Zimmer, J. Sierra, P. Bertuzzi et al. 2003. An overview of the crop model STICS. Eur. J. Agron. 18:309-332.

Carberry, P.S., R.C. Muchow, and R.L. McCown. 1989. Testing the CERES-Maize simulation model in a semi-arid tropical environment. Field Crops Res. 20:297-315.

Dobermann, A., D.T. Walters, F. Legoretta, T.J. Arkebauer, K.G. Cassman, R.A. Drijber, J.L. Lindquist, J.E. Specht, and H.S. Yang. 2005. Unlocking the secrets of carbon and nitrogen cycling in continuous corn and corn-soybean systems. In L.S. Murphy (ed.) Proc. of the 2005 Fluid Forum, Vol. 22, Scottsdale, AZ. 14-15 Feb. 2005. [CD-ROM]. Fluid Fertilizer Foundation, Manhattan, KS.

Dobermann, A., and H.S. Yang. 2004. In-season prediction of attainable maize yield using the Hybrid-Maize model. p. 235-236. In S.-V. Jacobsen et al. (ed.) VIII ESA Congress: European agriculture in a global context. The Royal Veterinary and Agric. Univ., Copenhagen, Denmark.

Hammer, G.L., M.J. Kropff, T.R. Sinclair, and J.R. Porter. 2002. Future contributions of crop modelling-From heuristics and supporting decision making to understanding genetic regulation and aiding crop improvement. Eur. J. Agron. 18:15-31.

Jones, C.A., and J.R. Kiniry. 1986. CERES-Maize: A simulation model of maize growth and development. Texas A\&M Univ. Press, College Station.

Jones, J.W., G. Hoogenboom, C.H. Porter, K.J. Boote, W.D. Batchelor, L.A. Hunt, P.W. Wilkens, U. Singh, A.J. Gijsman, and J.T. Ritchie. 2003. The DSSAT cropping system model. Eur. J. Agron. 18: 235-265.

Keating, B.A., B.M. Wafula, and J.M. Waitiki. 1992. Development of a modeling capability for maize in semi-arid eastern Kenya. ACIAR Proc. no. 41:26-33. Australian Centre for Int. Agric. Res., Canberra.

Kiniry, J.R., and A.J. Bockholt. 1998. Maize and sorghum simulation in diverse Texas environments. Agron. J. 90:682-687.

Kiniry, J.R., J.R. Williams, R.L. Vanderlip, J.D. Atwood, D.C. Reicosky, J. Mulliken, W.J. Cox, H.J. Mascagni, S.E. Hollinger, and W.J. Wiebold. 1997. Evaluation of two maize models for nine U.S. locations. Agron. J. 89:421-426.

Kropff, M.J., and H.H. van Laar. 1993. Modelling crop-weed interactions. CABI, Wallingford, Oxon, UK.

Lizaso, J.I., W.D. Batchelor, and M.E. Westgate. 2003. A leaf model to simulate cultivar-specific expansion and senescence of maize leaves. Field Crops Res. 80:1-17.

Ritchie, J.T., and G. Alagarswamy. 2003. Model concepts to express genetic differences in maize yield components. Agron. J. 95:4-9.

Ritchie, S.W., J.J. Hanway, and G.O. Benson. 1992. How a corn plant develops. Spec. Rep. 48. Available at http://maize.agron.iastate.edu/ corngrows.html (verified 27 Feb. 2006). Iowa State Univ., Coop. Ext. Serv., Ames.

Tokatlidis, I.S., and S.D. Koutroubas. 2004. A review of maize hybrids' dependence on high plant populations and its implications for crop yield stability. Field Crops Res. 88:103-114.

van Diepen, C.A., J. Wolf, H. van Keulen, and C. Rappoldt. 1989. WOFOST: A simulation model of crop production. Soil Use Manage. 5:16-24.

van Ittersum, M.K., P.A. Leffelaar, H. van Keulen, M.J. Kropff, L. Bastiaans, and J. Goudriaan. 2003. On approaches an applications of the Wageningen crop models. Eur. J. Agron. 18:201-234.

Yang, H.S., A. Dobermann, J.L. Lindquist, D.T. Walters, T.J. Arkebauer, and K.G. Cassman. 2004a. Hybrid-Maize: A maize simulation model that combines two crop modeling approaches. Field Crops Res. 87:131-154.

Yang, H.S., A. Dobermann, K.G. Cassman, and D.T. Walters. 2004b. Hybrid-Maize: A simulation model for corn growth and yield. Nebraska Coop. Ext. CD 9, Univ. of Nebraska, Lincoln. 